\title{
Research on the Development of SMEs in Jilin Province under the Great Trend
}

\author{
Shiyan Bai ${ }^{1, a}$, Junshu Zhang ${ }^{1, b}$ and Hongwei $\mathrm{Su}^{2, \mathrm{c}}$ \\ ${ }^{1}$ College of Humanities and Sciences of Northeast Normal University, Changchun, Jilin Province \\ 130021, China \\ 2 Jilin University, Changchun, Jilin Province 130000, China \\ a445996074@qq.com, b402472697@qq.com, 409577882@qq.com
}

Keywords: Energy Constraints; Finance; SMEs; Industry

\begin{abstract}
In 2015, China's SMEs will once again face serious challenges, and the situation is not optimistic. In this context, this paper, based on the two key constraints to China's economic development for energy and food, analyzes the current situation and the problems existed in the SMEs of Jilin province, and ultimately propose a five-point policy recommendation.
\end{abstract}

\section{Introduction}

It has been more than seven years since subprime mortgage crisis in 2008. On the surface, the subprime crisis seems to have been lopsided. In fact, however, after the subprime mortgage crisis, the governments have just transferred temporarily risks and postponed them, which separates themselves from the current international and domestic economic research, as well as the sided problem research and the short-term implementation of policy. Therefore, the study for the development of SMEs in Jilin Province should be based on international economic development trend, so as to determine the economic constraints for future development as well as their impact on China's domestic economy. In the international and domestic environment, this paper analyzes the problems in the development of SMEs considering the specific situation in Jilin province.

\section{Basic Situation}

Constraints in Economic Development. Jilin Province is China's important industrial (automotive industry) and agricultural base. And the oil and food are the two key elements of these two bases.

Energy constraints Energy has become one of the most important elements of today's world economic development. Especially, oil has been regarded as a resource of energy in the most representative. China is facing the following problems: Firstly, because crude oil is non-renewable, its price will certainly continue to rise in the future; secondly, the concentration of China's crude oil imports is very high. Once the exporter changes, China is likely to face oil shortage in the future. No matter what kind of result, China's domestic economy will suffer a serious impact, particularly for automobile industry which relies on crude oil to a high degree. The most important pillar industry of Jilin Province is the automobile industry. In addition to FAW, there are many small and medium enterprises supporting the industry. Once the car industry suffers from the oil shocks, Jilin's economy will be greatly suffered [1].

Food constraints Due to higher food production technology, contemporary society generally considers the shortage of food as a most unlikely problem. On the contrary, however, due to the growing world population, adjustment of the diet structure, the increase of transportation costs, as well as the appearance of monopoly, the food crisis led by environmental degradation may be reproduced in the future, which will be accompanied by two phenomena, i.e. the increase of food prices and the emergence of food shortages. Therefore, it will significantly improve the status of agriculture in the future. As the country's major grain-producing province, food production of Jilin Province accounts for one-tenth of the country, providing one tenth of the country's grain food. And the commodity rate is among the highest in the country. So for the future development of 
agriculture, how should Jilin Province formulate the strategy for the future economic development?

In short, the formulation of Jilin Province Economic Development Strategy should base on the future trend, which will make it possible to avoid disadvantages and exist among industries longer, thus contributing to the stable development of the province's economic and social development.

Development Status of SMEs and Private Enterprises in Jilin Province. As shown in Table 1, enterprises VAT and profit continues to increase. Firstly, since 2007 when implementing economic growth plan for SMEs, SMEs in Jilin Province has experienced the rapid economic development, playing a significant role in promoting the economic development of Jilin Province. Secondly, the number of enterprises increases and the scale expands. Thirdly, the contribution to economic development has been enhanced. SMEs and the private economy have become important driving forces for economic growth as well as the expansion of economic strength.

Table 1 Development status of SMEs and private enterprises in Jilin province

\begin{tabular}{|c|c|c|}
\hline & Year of 2015 & Year-to-year grow \\
\hline Contribution to GDP growth & $49.2 \%$ & $6.9 \%$ \\
\hline The major business income & 1.39 trillion RMB & $30.6 \%$ \\
\hline tax payments & 41.2 billion & $29 \%$ \\
\hline Employment & 4.7 million & $11 \%$ \\
\hline $\begin{array}{c}\text { Number of private companies } \\
\text { and sole traders }\end{array}$ & 133.5 million & $12 \%$ \\
\hline
\end{tabular}

However, the number of private enterprises per 10 thousand people in Jilin province is 42 , but 118 in Jiangsu, 96 in Zhejiang, 65 in Liaoning, and 53 in Shandong. The average asset of the private enterprises in Jilin province is only $5.5 \%$ of those of state-owned enterprises. In 2015, there are only three enterprises listed into the national top 500 private enterprises, including Dacheng, Xiuzheng, and Haoyue. The small and medium enterprises and private economy as a whole demonstrate the problem of "Big corporations are not big enough, and SMEs are too small" [2].

\section{Problems in the Development of SMEs in Jilin Province}

To research and analyze the problems in the development of SMEs in Jilin Province, it is necessary to divide the problems into short and long term problems.

Short-Term Problems. Heavy Tax burden in 2010, Jilin Province introduced 25 preferential policies to support the development of SMEs, in particular, giving them tax-related policy support, and to some extent, having promoted the development of SMEs. However, it should be noted that some of the tax burden of SMEs are mainly in the recessive state, and non-tax charges are usually more than the dominant taxes.

Shortage of funds - Difficult in Financing Jilin SMEs have financing problems resulting in shortage of funds, which may contain both internal and external reasons: firstly, the size and the level of credit for SMEs are low, limiting its financing capacity. Since the majority of our SMEs employ proprietorship and partnership with smaller scale, many SMEs do not establish a sound financial system, and some have not even set up accounting records, resulting into chaotic financial management. Their own credit ratings have been greatly reduced, leading to difficulty in passing credit eligibility assessment, thus seriously undermining their financing capacities.

Long-Term Problems. The increase of Costs In recent years, rising business costs of small and medium enterprises have severely compressed the profit margins. Firstly, there has been a significant increase in labor costs in our province. However, currently, small and medium enterprises are mainly labor-intensive industries, demanding more labors. And the impact of rising labor costs related these industries will be very significant. Secondly, because of its non-renewable nature, the price of crude oil will also be increasing in the long run. Again, financing costs continue to rise. Finally, rising labor costs, rising crude oil prices and rising financing costs will lead to the rise in prices of intermediate goods, thereby affecting the cost of products. 
The scale of enterprises being small, lacking sci-tech quality and competitiveness the total number and scale of SMEs in Jilin Province are smaller, which are generally in the general manufacturing and traditional service industries. Most products have low degree of innovation and technical content, resulting in low added values, thus further making the market less competitive, with small market share. If the province cannot change the business model for SMEs, it can only be in a vicious cycle, and ultimately treating from the market.

Narrow coverage of Industry cluster By 2015, the number of enterprises exceeding trillions of output value in Jilin province has reached 2, that of enterprises with the output value between 10 billion Yuan -100 billion has reached 5, that of enterprises with the output value more than 100 million Yuan has reached 323, representing a net increase of 51. At the time of increasing the enterprises and their scales, the role as a leading enterprise has been further remarked. For instance, FAW Group has contributed 51.3\% to the city's industrial growth rate, indicating that the development of industrial clusters in Jilin focused on the automotive industry, thus having low industrial cluster coverage. Especially as the industry leader, FAW Group lacks independent core property which does not have the advantage as an independent brand [3].

\section{Recommendations for the Development of Smes in Jilin Province}

Targeting the Taxation Overweight Problem in the Current Jilin Province, the Following Tax Measures Should Be Adopted. Firstly, lower taxes and reduced taxes are the trend of the future, and the earlier implementation will be better, providing more opportunity and time for the development of SMEs in our province. Secondly, the government must be conscious to guide the use of tax incentives and encourage SMEs first to invest in the province's industrial development; otherwise, simple tax relief will to some extent lose the enterprises' motivation. Finally, for the problem of SMEs' heavy non-tax revenue, the government should consider deregulation for SMEs, and the ignoring of the SMEs will lead to the retreating of SMEs from the real economy, which should re-select the investing mode. If SMEs in our province hope to gain substantial advance on the tax-reduction, non-tax revenue should be regulated [4].

For Smes' Financing Problems, the Government and the Enterprise Have to Work Together In Order to Diversify the Province's Limited Financing, Turning It Into Long-Term Financing. According to financing channels, corporate financing could be divided into internal financing and external financing. Internal financing mainly includes their own retained earnings, depreciation, etc., which can be used as a means to daily business financing. In Jilin Province, there are only a few companies which could create enough cash flow for business expansion and innovation through internal financing. The internal financing cannot meet the expanding needs of enterprises, etc., as well as the demands for product development and innovation. Therefore, companies need external financing. External financing has always been used as a primary means of business expansion and innovation. SME financing problem exists not only in China, it also exists in the United States, Europe and Japan and other developed countries. Therefore, governments need to constantly improve refinancing system in order to solve SMEs' problem of financing, and strive to create a favorable financing environment for SMEs. As the United States has created Microsoft, GOOGLE and many other world-renowned companies, their design of the SME financing system may be more worthy of our reference [5].

The Rise of Future Pressure on Business Costs Is An Unavoidable Reality, Which Would Be A Trend. Combined With the Specific Characteristics of the Province, The Government and Companies Need to Improve the Following Contents From Macro Scale and Micro Scale. Firstly, based on the aforementioned two important issues, i.e. energy and food, the province should design prior strategy to the development of industry, consciously supporting and guiding SMEs to invest in carefully selected key industries through preferential policies, financing and other measures. As mentioned earlier, even the automotive industry will be supported by our government in the future; the future will not be bright due to the constraints of energy, environment, transportation and other aspects. Therefore, it is necessary for the province to choose in advance and support the alternative industries [6]. 
Secondly, the central and local governments have always been stressing the importance of food, but the actual effect, for instance, the problems such as the aggression of farmland and grain reserves, proves that the practical emphasis on agriculture as the primary industry is continuingly declining. But based on previous analysis of the food crisis, the province should be more vigilant. Once there is the food crisis, the status of agriculture and its related industries will be significantly improved, and its role as a pillar of economic development in our province will also appear [7].

Thirdly, small and medium enterprises should change their concepts, and extend the industrial chain. Taking the agricultural products in our province as the example, the proportion of deep processing of agricultural products is rather low. The benefits enterprises brought by lengthened industry chain are the following three points. First, the profit margin for most of the agricultural companies is very low, which leads to weak anti-risk ability of these companies. The lengthening of industry chain will improve the stability of the company's performance, reducing investment risk as well as costs. Second, the higher the technological content of products, the deeper the degree of processing, and the value will be higher in general. Therefore, the extension of the industrial chain will help increase the profitability capacity. Third, due to the longer growing period of agricultural products, the business expansion speed will be constrained, facilitating the industrial chain expansion of the scale [8].

For Enterprises' Problems Such As Small-Scale, Low-Tech Quality and Lack of Competitiveness, Our Province Can Learn From Japan's Experience In Developing Smes. The main characteristics of the development of SMEs in Japan are to promote the establishment of cooperative relations between large enterprises and SMEs. According to statistics, $80 \%$ of Japanese small and medium enterprises have contract relations with large processing enterprises. The Japanese government has made positive efforts in the coordination of the relationship between large enterprises and SMEs, such as the establishment of "Fair Trade Commission", which is responsible for handling a variety of irrational phenomena in transactions; the initiation of appropriate laws and decrees, which have carried out certain restrictions to large enterprises' any contract fee delay paid to SMEs or branching out into traditional production areas [9].

Based on the Above Analysis Of Industrial Clusters, They Are Mainly In the Automotive Industry, Indicating Narrow Cluster Coverage. Theoretically, industrial cluster model can enhance regional economic competitiveness, but the key question is how to choose the industry, which is more suitable for the development of industrial clusters, rather than blindly believe that the more coverage, the better, the only result of which can only be broad but not fine. To this end, with the "Resource-oriented" concept, Jilin agriculture should be put at the core of industrial agglomeration, becoming bigger and stronger, even beyond the province's automobile industry, which will provide great benefits to the economy of our province in the long run [10].

\section{Summary}

The objective of this paper is to analyze the current situation and the problems existed in the SMEs in Jilin province, based on the two key constraints to China's economic development, that is, energy and food. The method used is qualitative analysis of the short-term and long-term problems in the development of SMEs in Jilin Province. Accordingly, results are decided that the main problems are heavy tax burden, shortage of funds, the increase of costs and the small scale of enterprises with lower sci-tech quality and competitiveness. Therefore, five recommendations are given to solve the problems. It is concluded that the SMEs in Jilin province may develop better with the implementation of recommended five policies.

\section{Acknowledgments}

The paper is the achievements of Philosophy and Social Science Fund of Jilin Province. 


\section{References}

[1] WC Li, H Pan and XW Ju, Path Analysis to Achieve the Transfer of Jilin Economic Growth Pattern under the New Normal Background, J of Northeast Normal University, 278(2015) No. 6, p98

[2] HM Zhang: The Coordinated Development of Energy Economy in Jilin Province under Environmental Constraints ( PH. D, Chinese Academy of Sciences, China, 2014), p101-103

[3] YK Zheng, YB Lv, Strategic Research on the Development of Automobile Industry in Jilin Province under The New Situation, Journal of Changchun University, 26(2016).No. 7

[4] JR Zhang: SME Development Report of Zhejiang Province (Zhejiang Industrial and Commercial University Press, China, 2014) p.26

[5] H Chen: Financing Problems and the Institutional Innovation of Chinese SMEs (PH.D, Fujian Normal University, China, 2013), p121

[6] XN Zhao, XD Wang, Path Research on Rural Income Doubling in Jilin Province, Taxation and Economy, 207(2016)No.4, p99

[7] N Liu, Dynamic Impact of Energy Price Volatility on Food Production Costs, Trade Research, 23(2014) No.4, p34

[8] H Pan, G Liu, Empirical Analysis of Agricultural Scientific and Technological Progress And Economic Growth in Jilin Province, Northeast Asia Forum, 18(2009) No.6, p96

[9] SX Yao, ZhH Pan, Japanese SMEs' Implications on SMEs in China, Journal of Southwest University for Nationalities, 25(2004) No.3

[10]L Li, Research on Innovative Problems In SMEs Under The New Normal State, Journal of Inner Mongolia University of Finance and Economics, 14(2016) No.2, p53 